\title{
Exploring knowledge, attitudes, and practices toward older adults with hypertension in primary
} care

\section{Luckwirun Chotisiri \\ Khemika Yamarat \\ Surasak Taneepanichskul \\ College of Public Health Sciences, Chulalongkorn University, Pathumwan, Bangkok, Thailand}

Correspondence: Luckwirun Chotisiri College of Public Health Sciences, Chulalongkorn University, Institute Building 2-3, Soi Chulalongkorn 62, Phyathai Road, Pathumwan, Bangkok 10330, Thailand

Tel +66896698198

Email siriwanc@yahoo.com
This article was published in the following Dove Press journal:

Journal of Multidisciplinary Healthcare

26 October 2016

Number of times this article has been viewed

Purpose: High blood pressure increases the risk of cardiovascular and kidney diseases. The purpose of this study was to explore a baseline of hypertension knowledge, attitudes, and practices among older adults with hypertension at a sub-district Health Promoting Hospital in the Pathum Thani province of Thailand.

Patients and methods: A cross-sectional study was conducted at the outpatient clinic of the sub-district Health Promoting Hospital, one of the primary care sectors, between January and March 2015, and a total of 144 cases were recruited. All clinical parameters were collected and a structured questionnaire was used. Data were analyzed by means of descriptive statistics and chi-square tests.

Results: Most of the participants (74.3\%) were females, and their mean age was 66.1 years. Two-thirds (66.7\%) were married, unemployed/retired (67.4\%), and had completed elementary education (79.2\%). The screenings showed that their mean blood pressure was $136.4( \pm 14.4) / 79.2$ $( \pm 10.1) \mathrm{mmHg}$, the group's mean body mass index was $24.9 \mathrm{~kg} / \mathrm{m}^{2}\left( \pm 3.6 \mathrm{~kg} / \mathrm{m}^{2}\right)$, and their mean waist circumference was $88.6 \mathrm{~cm}( \pm 7.1 \mathrm{~cm})$ for males and $85.7 \mathrm{~cm}( \pm 6.8 \mathrm{~cm})$ for females. In addition, their mean score of hypertension knowledge was high, and most of the participants had a neutral attitude toward hypertension; their practices in terms of dietary and exercise habits for controlling blood pressure were low in nature.

Conclusion: This study indicated that increasing patients' practices would be useful for promoting their healthy behaviors to achieve blood pressure control.

Keywords: aging, blood pressure, community, health behavior, screening

\section{Introduction}

Hypertension is a major global health problem. The Global Burden of Disease Study has indicated that premature deaths, disability, stroke, and heart disease are related to increased blood pressure levels. ${ }^{1-3}$ Higher incidence rates of hypertension are attributed to population growth, aging, and behavioral risk factors such as unhealthy food intake, physical inactivity, obesity, smoking, excessive drinking of alcohol, and chronic stress. ${ }^{4}$ Uncontrolled blood pressure is associated with an increased risk of heart disease, stroke, and kidney disease. ${ }^{5,6}$

Recently, the prevalence of hypertension has been increasing, and the number of newly diagnosed cases of hypertension has risen in all regions of Thailand. ${ }^{3,6}$ Underlying demographic characteristics that have an influence on high blood pressure and vulnerability to various health factors include age, sex, body mass index (BMI), waist circumferences, and a family history of hypertension. ${ }^{3}$ Furthermore, lifestyle habits 
such as unhealthy food intake, physical inactivity, cigaret smoking, alcohol use, chronic stress, and insufficient sleep also increase the risk of hypertension. ${ }^{7-10}$

Both pharmacotherapy and lifestyle modifications are recommended treatments for hypertension. However, prevention of high blood pressure and concomitant cardiovascular disease, changes in medication adherence and lifestyle therapies that require a deeper understanding of knowledge-based awareness, and patients' behavioral adaptation are also recommended. ${ }^{11-13}$ Hence, it is necessary to explore the knowledge, attitudes, and behaviors or practices of hypertensive patients who are at an increased risk of failing to reach their targeted blood pressure control levels, particularly those involved in community-based care. It was anticipated that such a study might help further explain individuals' knowledge, attitudes, and lifestyles. For this reason, the community-based survey conducted in this study was aimed at assessing the hypertension knowledge, attitudes, and practices among hypertensive patients seeking health care services at Buengkhamphroi Health Promoting Hospital (HPH), Pathum Thani Province, Thailand.

\section{Patients and methods Study area and participants}

A cross-sectional study was conducted at one of the 12 primary care settings, namely Buengkhamphroi Health Promoting Hospital (HPH), located in Buengkhamphroi subdistrict, Lamlukka district, Pathum Thani Province. This is a semi-urban area close to the Bangkok Metropolitan Administration. The sample size of the study was 144 participants. The study participants were 55 years old or older, and both males and females participated in the study. All had been diagnosed with hypertension and were currently undergoing treatment and receiving regular follow-ups at the hypertension clinic. Individuals who were suffering from serious chronic illnesses or who were not willing to participate in the study were excluded. The survey was carried out between January and March 2015.

\section{Instruments}

The measurement tools used in this study consisted of digital blood pressure measurement devices, a stadiometer with a weight scale, and a fabric tape measure to measure waist circumferences. A five-part questionnaire was also employed to collect the following data: 1) general characteristic, 2) knowledge about hypertension, 3) attitudes toward hypertension, 4) practice of hypertension, and 5) past history and other health risk factors. Data collection were undertaken in three steps. First, preparations began with the validation of the questionnaire by three public health experts regarding what to be measured and what not to measured; second, a coefficient of those was completed; and third, a coefficient of $\sim 0.5$ was valid at 0.73 , by the Items-Objective Congruence Index. Furthermore, a pilot study was also conducted to test the reliability of the questionnaire, which refers to the accuracy and consistency of information obtained in a study; the 10-question knowledge survey among old patients with hypertension had good reliability (Kuder-Richardson-20 coefficient was 0.70 ). Also, the Cronbach's coefficient alpha for the attitudes toward hypertension questionnaire was 0.74 , which was considered acceptable. Clinical parameters were defined in the subsequent step. The research team introduced themselves to the prospective participants, explained the aims of the study, and obtained written consent from the participants who met the inclusion criteria and were willing to participate in the study. The participants underwent a complete physical examination, including measurements of their body weight and height. BMI was calculated as weight/height $\left(\mathrm{kg} / \mathrm{m}^{2}\right)$, and waist circumference was also measured. ${ }^{14,15}$ This study defined hypertension based on a diagnosis of hypertension that required a physician's treatment. Blood pressure was taken using a digital blood pressure measurement device after a 10 -minute rest in a sitting position and following standard procedures. Two readings of mean measures were used in the analysis; however, if a high systolic blood pressure (SBP) measurement was greater than $5 \mathrm{mmHg}$, a third reading was taken. Following this procedure, the lowest of the three readings was taken as the blood pressure measurement. Using JNC 7, classification of blood pressure for adults ${ }^{5}$, pre-hypertension was diagnosed when SBP was 120-139 $\mathrm{mmHg}$ and diastolic blood pressure (DBP) was 80-89 mmHg. Hypertension stage 1 was diagnosed when SBP was 140-159 mmHg and DBP was 90-99 $\mathrm{mmHg}$, and hypertension stage 2 was diagnosed when SBP was $\geq 160$ $\mathrm{mmHg}$ and DBP was $\geq 100 \mathrm{mmHg}$. In addition, the lowest and highest groups from those categories were observed. ${ }^{16}$ The last step of the data collection process was a approximately 30-minute individual interview with each participant based on a semi-structured questionnaire. It is worth noting that all data were collected by well-trained village health volunteers and trained nurses from the outpatient clinic of the selected health promoting hospital.

The total possible score for knowledge of hypertension was 10 points, the total possible score for attitude toward 
hypertension was 30 points, and the total possible score for practice was 60 points. The mean standard deviation (SD) of knowledge of hypertension was used to categorize the scores as "high", "moderate", or "low". A high level of hypertension knowledge was defined as a score greater than or equal to mean $+\mathrm{SD}$, a moderate level of knowledge was defined as a score between mean $\pm \mathrm{SD}$, and a low level of knowledge was defined as a score less than or equal to mean - SD.

Regarding attitudes toward hypertension, the mean and SD were also used to categorize the participants' scores as positive, neutral, or negative. A positive attitude was defined as a score greater than or equal to mean $+\mathrm{SD}$. A neutral attitude was defined as a score between mean \pm SD. A negative attitude was defined as a score less than or equal to mean - SD.

Practice was categorized into four subgroups: healthy diets, unhealthy diets, physical activity and exercise, and stress-relieving activities. Healthy diets were defined as patients' decision (weekly) consumption of vegetables, highfiber foods, and few sweet fruits; drinking lots of water (at least $1 \mathrm{~L} /$ day); and cutting down on sodium intake. On the other hand, unhealthy diets were defined as frequent (weekly) consumption of high-salt, high-fat, and high-energy foods. In addition, the study participants were considered physically active when they engaged in any form of exercise for 30 minutes at a time at least three times per week. Finally, stress-relieving activities were defined as the availability of leisure time and the sleep pattern followed. In this study, if the practice was done on most days of the week or 5-7 days, a score of 3 points was given; a score of 2 points if performed for 3-4 days/week; a score of 1 point if performed only once or twice per week; and a score of 0 point was given if self-care activities were not performed at all. The mean values and SD of practice were categorized as follows: high, moderate, and low. A high level of practice was defined as a score greater than or equal to mean $+\mathrm{SD}$, a moderate level of practice was defined as a score between mean $\pm \mathrm{SD}$, and a low level was defined as a score less than or equal to mean $-\mathrm{SD}$, respectively.

\section{Data analyses}

Data analyses were conducted using SPSS statistical package version 16 (SPSS Inc., Chicago, IL, USA). Descriptive statistics, including frequency distribution, percentage, mean, and $\mathrm{SD}$, were used to describe the following demographic characteristics of the participants: chronic conditions and risk factors, clinical assessment, clinical parameters, knowledge, attitudes, and practices related to hypertension.

\section{Ethical considerations}

This study was approved by the Ethics Review Committee for Research Involving Human Research Subjects, Health Sciences Group of Chulalongkorn University (COA No.178/2557). Prior to participating in the study, the study objectives and data collection procedures were fully explained to the participants who then signed a written informed consent form to indicate their willingness to participate in the study.

\section{Results}

Table 1 describes the demographic characteristics of the 144 study participants. Approximately one-thirds (74.3\%) were females. Their mean age was $66.1 \pm 9.0$ years. Furthermore, approximately two-thirds $(66.7 \%)$ were married, $79.2 \%$ had completed elementary education, and $67.6 \%$ were not employed (housewives/retirees). Most of the participants were non-smokers and non-alcoholics. Also more than $50 \%$ reported that their family history of hypertension was unknown, and most of them ( $83.3 \%$ ) had been diagnosed with hypertension and had been taking antihypertensive drugs for more than 5 years. Moreover, nearly $30 \%$ of the participants had other health issues, such as diabetes mellitus, blurred vision, and hearing loss. With regard to clinical assessments, it was found that their mean SBP was 136.4 \pm 14.4 $\mathrm{mmHg}(43.1 \%)$ and DBP was $79.2 \pm 10.1 \mathrm{mmHg}(53.5 \%)$. In addition, their mean BMI was $24.9 \pm 3.6 \mathrm{~kg} / \mathrm{m}^{2}(43.8 \%)$.

Table I Demographic characteristics of study participants

\begin{tabular}{|c|c|c|}
\hline Variables & $N(n=144)$ & $\%$ \\
\hline \multicolumn{3}{|l|}{ Demographic characteristics } \\
\hline Age $6 I-70$ years $(66.1 \pm 9.0)$ : age range $55-80$ years & 58 & 40.3 \\
\hline Female & 107 & 74.3 \\
\hline Married & 96 & 66.7 \\
\hline Elementary education & 114 & 79.2 \\
\hline Housewives/retirees & 106 & 67.6 \\
\hline \multicolumn{3}{|l|}{ Chronic illnesses and health risk factors } \\
\hline Non-smokers & 108 & 75.0 \\
\hline Non-alcoholics & 109 & 75.7 \\
\hline Family history of hypertension: unknown & 82 & 56.9 \\
\hline Duration of hypertension $\geq 5$ years $(9.0 \pm 3.4)$ & 120 & 83.3 \\
\hline Duration of taking medication $\geq 5$ years $(9.0 \pm 3.4)$ & 118 & 81.9 \\
\hline Hypertension with other problems & 75 & 52.1 \\
\hline \multicolumn{3}{|l|}{ Clinical parameters } \\
\hline \multicolumn{3}{|l|}{ Blood pressure: taking $\geq$ I antihypertensive drug(s) } \\
\hline SBP I20-I39 mmHg (I36.4 144.4$)$ & 62 & 43.1 \\
\hline $\mathrm{DBP}<80 \mathrm{mmHg}(79.2 \pm 10.1)$ & 77 & 53.5 \\
\hline Body mass index $>25 \mathrm{~kg} / \mathrm{m}^{2}(24.9 \pm 3.6)$ & 63 & 43.8 \\
\hline \multicolumn{3}{|l|}{ Waist circumferences (men: $n=37$, females: $n=107$ ) } \\
\hline$>90 \mathrm{~cm}$ for males $(88.6 \pm 7.1)$ & 17 & 13.9 \\
\hline$>80 \mathrm{~cm}$ for females $(85.7 \pm 6.8)$ & 77 & 53.9 \\
\hline
\end{tabular}

Abbreviations: SBP, systolic blood pressure; DBP, diastolic blood pressure. 
Finally, regarding waist circumferences, it was found that $13.9 \%$ of male participants had a waist circumference $>90$ $\mathrm{cm}(13.9 \%)$, with a mean waist circumference of $88.6 \pm 7.1$ $\mathrm{cm}$, and more than half of female participants $(53.9 \%)$ had a waist circumference $>80 \mathrm{~cm}$, with a mean of $85.7 \pm 6.8 \mathrm{~cm}$.

Of the 144 participants, $62.5 \%$ had a high score of knowledge of hypertension, and most of them $(77.8 \%)$ had a neutral attitude toward hypertension. However, it is worth noting that the number of participants who had either positive or negative attitudes toward hypertension were equal. Moreover, the overall score regarding participants' practice of hypertension was at a moderate level (70.1\%). The findings of healthy diets, unhealthy diets, physical activity and adherence to adherence, and stress-relieving activities are presented in Table 2.

\section{Discussion}

According to the findings, the majority of the participants were females, had hypertension, had been taking medication for 5 or more years, had been able to control their blood pressure to less than 140/90 mmHg, and had a BMI of $24.9 \pm 3.6 \mathrm{~kg} / \mathrm{m}^{2}$. It is worth noting that the proportions of overweight participants $\left(\mathrm{BMI}>25 \mathrm{~kg} / \mathrm{m}^{2}\right)$ and the participants whose waist circumferences were greater than the criteria ( $>90 \mathrm{~cm}$ for males and $>80 \mathrm{~cm}$ for females) were similar to those observed. ${ }^{6}$ Similarly, a previous study found that the average BMI and waist circumferences in both sexes, after socioeconomic factors, diet habit, physical activity, and social context had been taken into consideration, had changed over the past decade. One reason which can be explained that as more hypertensive patients live in urban areas, they might have adopted the unhealthy lifestyles of urbanites - for example, modern dietary habits such as consuming Thai food - which differ from the past. ${ }^{3,6,17}$ In addition, the study findings shed light on other physiological risk factors that were likely related to disease burden, such as being overweight, having a waist circumference greater than $80 \mathrm{~cm}$ in females, and being menopausal, all of which change progressively with age..$^{3,6,17,18}$ The clinical parameters for males require further observation.

Table 2 Findings regarding knowledge, attitude, and practice toward hypertension

\begin{tabular}{lll}
\hline Variables & N (n= I44) $\%$ \\
\hline Score of knowledge about hypertension: high & 90 & 62.5 \\
Score of attitude toward hypertension: neutral & 112 & 77.8 \\
Score of overall practice: moderate & $10 \mathrm{I}$ & 70.1 \\
Four subgroups of practices related to hypertension & & \\
Healthy diets: 3-4 days/week & 72 & 50.0 \\
Unhealthy diets: I-2 days/week & 124 & 86.1 \\
Physical activity and exercise: I-2 times/week & 131 & 91.0 \\
Stress-relieving activities: I-2 times/week & 126 & 87.5 \\
\hline
\end{tabular}

The findings of this study showed a high mean score of knowledge on hypertension and a neutral attitude toward hypertension among the study participants. This could be explained as a response to Thailand's Healthy Lifestyle Strategic Plan (2010-2020), one of the campaigns of the Ministry of Public Health that aims to promote healthy lifestyles among Thai citizens, and particularly for those with chronic diseases, including hypertension. These national projects have focused on practices for preventing non-communicable diseases by means of behavioral adaptations such as maintaining a balanced diet, engaging in adequate levels of physical exercise, and adopting suitable emotional management techniques, as national health priorities in the primary health care sectors. ${ }^{19}$ Having access to this information via the mass media and through health care providers allows patients to gain knowledge and promote attitude changes regarding disease. ${ }^{20}$ However, in this study, the participants' mean scores of overall practice were at a moderate level, particularly with regard to healthy diets and physical activity, which was clearly inadequate. ${ }^{16,21}$ Surprisingly, we found that most of the participants reported altering their lifestyle to avoid an unhealthy diet only once or twice weekly $(86.1 \%)$, and they managed their stress by engaging in relaxing activities only 1-2 days per week $(87.5 \%)$. This might have been due to individual reasons, the influence of mass media, and social context, as in the Thai culture, individuals prefer to spend time engaged in family activities such as preparing food and cooking by themselves, which may have led to the consumption of unhealthy foods, despite the emphasis of the national health promotion campaign on increased consumption of fruit and vegetables via various channels. ${ }^{19,22}$

The limitation of this study is patients with uncontrolled hypertension or blood pressure greater than $160 / 100 \mathrm{mmHg}$ did not address according to universal health coverage and the referral system of the Ministry of Public Health Policy, the service potential of primary health care unit addresses only patients who are able to control their blood pressure. ${ }^{16,23}$ Therefore, further research should be considered to include other groups. Another limitation of this study is selection bias that might have occurred due to the sample of older adults with hypertension who participated in the study. Furthermore, the sample size of this study was not large. With these limitations in mind, it is advisable to add more clinics of other health-promoting hospitals to research settings for future studies. If possible, data collection could be done using more instruments to triangulate the study findings. It is also worth noting that, in the present study, other factors such as patients' beliefs, alternative treatments and use of herbal supplements, and influence of various media outlets might 
have affected the patients' idea that illness and lifestyle habits cannot be controlled. It is also possible that different findings may have been obtained among a more homogeneous patient sample with a specific chronic illness, such as diabetes mellitus and kidney disease. Finally, it is possible that the data collected in this study could have been biased due to the participants' moods, staff members' intention, and the duration of interviews. Each of these may have played some role in the data collection procedures used throughout the study.

\section{Conclusion}

The findings of this study revealed that participants' scores of knowledge on hypertension ranged from moderate to high, and their mean attitude score toward hypertension was neutral. In addition, their efforts to control their blood pressure in terms of healthy diets and physical activity were inadequate. Therefore, this study has highlighted the need to increase patients' practice, which would be useful in controlling blood pressure, allowing them to reduce health risk factors among older adults with hypertension. Further research is needed to promote individual perform on their own within the cultural and social contexts of the community that could help result in positive health outcomes of hypertensive patients.

\section{Acknowledgments}

The authors would like to express their sincere gratitude for the support and assistance from Associate Professor Dr Wiroj Jiamjarasrangsi MD, Associate Professor Panya Kaimuk MD, and health care teams of Buengkamphroi Health Promoting Hospital, Lamlukka Community Hospital, and Lamlukka District Public Health Office in Pathum Thani Province. The study has been generously supported by the Higher Education Promotion and National Research University Project of Thailand, Office of Higher Education Commission (AS1148A-55), and the Ratchadaphiseksomphot Endowment Fund of Chulalongkorn University (RES560530243-AS).

\section{Disclosure}

The authors report no conflicts of interest in this work.

\section{References}

1. Campbell NR, Lackland DT, Lisheng L, Niebylski ML, Nilsson PM, Zhang XH. Using the Global Burden of Disease Study to assist development of nation-specific fact sheets to promote prevention and control of hypertension and reduction in dietary salt: a resource from the World Hypertension League. J Clin Hypertens. 2015;17(3):165-167.

2. World Health Organization. Noncommunicable Diseases in the SouthEast Asia Region: Situation and Response 2011. Geneva: World Health Organization; 2011.

3. Aekplakorn W, Sangthong R, Kessomboon P, et al. Changes in prevalence, awareness, treatment and control of hypertension in Thai population, 2004-2009: Thai National Health Examination Survey III-IV. J Hypertension. 2012;30(9):1734-1742.
4. World Health Organization. A global brief on Hypertension: Silent killer, global public health crisis (World Health Day 2013). 2013.

5. Chobanian AV, Bakris GL, Black HR, et al. Seventh report of the joint national committee on prevention, detection, evaluation, and treatment of high blood pressure. Hypertension. 2003;42(6):1206-1252.

6. Tiptaradol S, Aekplakorn W. Prevalence, awareness, treatment and control of coexistence of diabetes and hypertension in Thai population. Int J Hypertens. 2012;2012:1-7.

7. Chongthawonsatid S. Demographic factors and health care behavior of hypertension disease in Thailand. Silpakorn U Science \& Tech J. 2015;9(1):9-16.

8. Gangwisch JE, Heymsfield SB, Boden-Albala B, et al. Short sleep duration as a risk factor for hypertension analyses of the first national health and nutrition examination survey. Hypertension. 2006;47(5): 833-839.

9. Koti A, Roetzheim RG. Patient factors associated with documented provision of JNC 7-recommended hypertension care at an academic family medicine office. J Am Board Fam Med. 2015;28(1):97-104.

10. Thawornchaisit P, de Looze F, Reid CM, Seubsman S, Sleigh A, Team TCS. Health-risk factors and the prevalence of hypertension: cross-sectional findings from a national cohort of 87,143 Thai Open University students. Glob J Health Sci. 2013;5(4):126-141.

11. Rahman ARA, Wang J-G, Kwong GMY, Morales DD, Sritara P, Sukmawan R. Perception of hypertension management by patients and doctors in Asia: potential to improve blood pressure control. Asia Pac Fam Med. 2015;14(1):2.

12. Barr PJ, Brady SC, Hughes CM, McElnay JC. Public knowledge and perceptions of connected health. J Eval Clin Pract. 2014;20(3): 246-254.

13. Cohn ES, Cortés DE, Fix G, Mueller N, Solomon JL, Bokhour BG. Habits and routines in the daily management of hypertension. $J$ Health Psychol. 2012;17(6):845-855.

14. WHO Expert Consultation. Appropriate body-mass index for Asian populations and its implications for policy and intervention strategies. Lancet. 2004;363(9403):157-163.

15. Wildman RP, Gu D, Reynolds K, Duan X, He J. Appropriate body mass index and waist circumference cutoffs for categorization of overweight and central adiposity among Chinese adults. Am J Clin Nutr. 2004;80(5):1129-1136.

16. Buranakitjaroen P, Wataganara T, Bunnag P, Puavilai W, Tejavanija S. 2015 Thai Hypertension Guideline Bangkok: Thai Hypertens Soc; 2015:1-10.

17. Aekplakorn W, Bruce Neal M, Chariyalertsak S, Kunanusont C, Phoolcharoen W, Suriyawongpaisal P. Prevalence and determinants of overweight and obesity in Thai adults: results of the Second National Health Examination Survey. J Med Assoc Thai. 2004;87(6): 685-693.

18. Chen SC, Lo TC, Chang JH, Kuo HW. Variations in aging, gender, menopause, and obesity and their effects on hypertension in Taiwan. Int J Hypertens. 2014;2014:1-7.

19. Supornsilaphachai C. Evolution of salt reduction initiatives in Thailand: lessons for other countries in the South-East Asia Region. WHO Regional Health Forum. 2013;17(1):61-71.

20. Geaney F, Fitzgerald S, Harrington JM, Kelly C, Greiner BA, Perry IJ. Nutrition knowledge, diet quality and hypertension in a working population. Prev Med Rep. 2015;2:105-113.

21. Alonso A, de la Fuente C, Martín-Arnau AM, de Irala J, Martínez JA, Martínez-González MÁ. Fruit and vegetable consumption is inversely associated with blood pressure in a Mediterranean population with a high vegetable-fat intake: the Seguimiento Universidad de Navarra (SUN) Study. Br J Nutr. 2004;92(2):311-319.

22. Bureau of Policy and Strategy, Ministry of Public Health. Thailand Healthy Lifestyle Strategic Plan, B.E. 2554-2563 [2011-2020]. Nonthaburi: Bureau of Policy and Strategy; 2012.

23. Tangcharoensathien V, Swasdiworn W, Jongudomsuk P, Srithamrongswat $\mathrm{S}$, Patcharanarumol W, Thammathat-aree T. Universal coverage scheme in Thailand: Equity Outcomes and Future Agendas to Meet Challenges. 2010;43. 
The Journal of Multidisciplinary Healthcare is an international, peerreviewed open-access journal that aims to represent and publish research in healthcare areas delivered by practitioners of different disciplines. This includes studies and reviews conducted by multidisciplinary teams as well as research which evaluates the results or conduct of such teams or health care processes in general. The journal covers a very wide range of areas and welcomes submissions from practitioners at all levels, from all over the world. The manuscript management system is completely online and includes a very quick and fair peer-review system. Visit http://www.dovepress.com/ testimonials.php to read real quotes from published authors. 